\title{
Significance of Transferrin in Iron Delivery to the Brain
}

\author{
Atsushi Takeda* \\ Department of Medical Biochemistry, School of Pharmaceutical Sciences, University of Shizuoka, 52-1 Yada, Shizuoka 422-8526, \\ Japan
}

(Received August 23, 2001)

\begin{abstract}
The role of transferrin in iron delivery to tissues is described. Transferrin-dependent iron uptake by erythroid cells in the bone marrow is essential for the development of erythrocytes, while nontransferrin-bound iron can be taken up in tissues such as liver. On the basis of the evidence that iron distribution in the body is changed by iron saturation of plasma transferrin, the role of transferrin in iron delivery to the brain is reviewed. In the case of transient iron saturation of plasma transferrin, ${ }^{59} \mathrm{Fe}$ concentrations in the brain of iron-loaded mice are approximately $40-50 \%$ of those of control mice in all brain regions tested except the choroid plexus, in which the ${ }^{59} \mathrm{Fe}$ concentration is equal. A similar distribution of ${ }^{59} \mathrm{Fe}$ in the brain is also observed in neonatal hypotransferrinemic (HP) mice, which have a splicing defect in the transferrin gene, resulting in $<1 \%$ of the normal plasma levels of transferrin. These results suggest that transferrin-bound iron is responsible for the fraction of iron in the circulation that enters the brain. On the other hand, the iron concentration in the brain of HP mice is approximately three times higher than that in nonmutant mice. It is likely that the management of iron is affected in the brain of HP mice. Brain transferrin may be involved in the management of iron in the brain.
\end{abstract}

Key words — brain, iron, transferrin, homeostasis, iron saturation of transferrin, choroid plexus

\section{INTRODUCTION}

Transferrin, a plasma glycoprotein, has been considered as an important molecule for the transport of iron. ${ }^{1,2)}$ Transferrin-dependent iron uptake by erythroid cells in the bone marrow is essential for the development of erythrocytes. ${ }^{3-5)}$ Iron-deficient anemia is widely known in humans and animals. Transferrin is synthesized primarily in the liver, while a significant amount is also produced in the brain. ${ }^{6-10)}$ In the brain, transferrin mRNA exists in oligodendrocytes and also in the choroid plexus in concentrations equal to that found in liver.

Iron is essential for the development and functioning of the brain. ${ }^{11,12)}$ Iron concentrations in the human brain are approximately five times higher in adults (approximately $65 \mu \mathrm{g} / \mathrm{g}$ wet weight) than in infants below 1 year of age, ${ }^{13)}$ suggesting that iron

*To whom correspondence should be addressed: Department of Medical Biochemistry, School of Pharmaceutical Sciences, University of Shizuoka, 52-1 Yada, Shizuoka 422-8526, Japan. Tel.: +81-54-264-5700; Fax: +81-54-264-5705; E-mail: takedaa@ushizuoka-ken.ac.jp is a required component for brain functions. In the brain, iron is found in oligodendrocytes in high density and is required for myelin production. ${ }^{14,15)}$ Iron uptake is the highest during postnatal development at a time that coincides with peaks in brain growth and myelin production, ${ }^{16)}$ and an insufficient iron supply to the brain results in hypomyelination. ${ }^{17)}$ Thus an adequate supply of iron is important for brain development. Recent evidence suggests a functional difference between transferrin synthesized in the brain and in other tissues such as liver and a specific role of transferrin in oligodendrocyte maturation and in myelinogenesis. ${ }^{18)}$

\section{Hemochromatosis and Hypotransferrinemia}

Hereditary hemochromatosis is characterized by the triad of increased iron absorption by gastrointestinal cells, high or total iron saturation of plasma transferrin, and abnormal iron deposition in the tissues, especially in the liver. ${ }^{19,20)}$ A similar pattern of liver iron deposition is also observed in the hypotransferrinemic (HP) mice, ${ }^{21)}$ which have a point mutation or small deletion in the transferrin gene 
and produce $<1 \%$ of the normal circulating level of plasma transferrin. ${ }^{22)}$ The affected animals are small, pale, and severely anemic at birth and require weekly injections of serum or purified transferrin for survival. The liver iron deposition in the two disorders of hereditary hemochromatosis and hypotransferrinemia may be due to saturation or lack of transferrin.

\section{Iron Distribution in the Brain under Iron Satu- ration of Plasma Transferrin}

Craven et al. reported the tissue distribution of nontranferrin-bound ${ }^{59} \mathrm{Fe}$ in the case of transient saturation of plasma transferrin by intravenous injection of ferric citrate. ${ }^{23)}$ Plasma clearance of nontransferrin-bound ${ }^{59} \mathrm{Fe}$ is very high. In ironloaded rats, $>80 \%$ of the injected radioactivity is eliminated from the plasma by $30 \mathrm{~s}$, probably owing to rapid uptake of nontransferrin-bound ${ }^{59} \mathrm{Fe}$ by the liver. On the basis of the evidence that tissue iron distribution is changed by iron saturation of plasma transferrin, the influence of iron saturation of transferrin in iron delivery to the brain was studied by means of brain autoradiography. ${ }^{24)}$ Twentyfour hours after intravenous injection of ${ }^{59} \mathrm{FeCl}_{3}$ into iron-loaded mice, ${ }^{59} \mathrm{Fe}$ distribution in the brain was different between control and iron-loaded mice. ${ }^{59} \mathrm{Fe}$ concentrations in the brain of iron-loaded mice were approximately $40-50 \%$ of those of control mice in all brain regions tested except the choroid plexus, in which the ${ }^{59} \mathrm{Fe}$ concentration was equal. Transferrin-bound iron may be responsible for the fraction of iron in circulation that enters the brain (Fig. 1).

Regarding iron delivery at the blood brain-barrier, two hypotheses are proposed. One hypothesis suggests that a large portion of holo-transferrin taken up by the capillary endothelial cells is recycled to the blood as apo-transferrin. Iron released from transferrin in endosomal compartments is transcytosed by unknown mechanisms. ${ }^{25,26)}$ The other hypothesis suggests that transferrin-bound iron is transcytosed predominantly across the capillary endothelial cells. ${ }^{27-29)}$ The data showing that transferrin in the brain of adult HP mice is of exogeneous origin support the latter hypothesis. ${ }^{30}$

In the brain in hereditary hemochromatosis, iron deposition has not been described as a pathological phenomenon and this disease is not usually associated with neurological symptoms. ${ }^{31)}$ Sotogaku et al. demonstrated that the iron concentration in the brain, unlike in the liver, only increases slightly after persistent iron overloading. ${ }^{32)}$ Therefore it is likely that
Physiological iron delivery

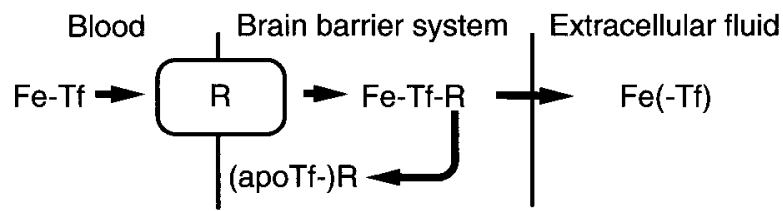

Iron delivery under iron saturation of transferrin

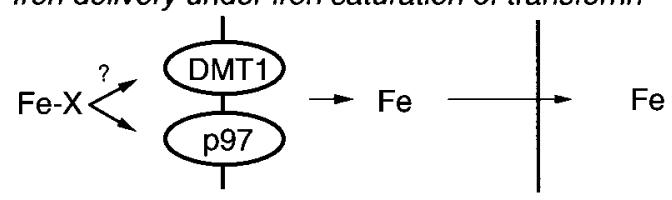

Fig. 1. Iron Transport into the Brain Across the Brain Barrier System

The receptor-mediated endocytosis of iron-transferrin (Fe-Tf) is important for physiological delivery of iron to the brain. The mechanism via iron transporters such as DMT1 and p97 might serve for iron delivery in the brain barrier system under iron saturation of plasma transferrin. In the brain, iron-transferrin may be taken up in neurons via receptormediated endocytosis, ${ }^{51)}$ while nontransferrin-bound iron may be taken up in glial cells. ${ }^{39)} \mathrm{R}$, transferrin receptor; Fe-X, nontransferrin-bound iron.

nontransferrin-bound iron present in the circulation of hemochromatosis patients is of little significance as a cause of pathological iron accumulation in the brain.

\section{Nontransferrin-Mediated Iron Transport into the Brain}

Blood radioactivity of iron-loaded mice is approximately $10 \%$ of that of control mice; the decrease in ${ }^{59} \mathrm{Fe}$ concentration in the brain by iron loading is not parallel with that in the plasma. ${ }^{24}$ There is the possibility that a portion of nontransferrin-bound ${ }^{59} \mathrm{Fe}$ is transported into the brain (Fig. 1). p97 (melanotransferrin), an iron-binding protein, is reported to be present in brain capillary endothelium and a subset of microglial cells in humans. ${ }^{33,34)}$ DMT1, a divalent metal transporter, which is involved in the transport of ferrous ion via a ferrireductase, is abundantly expressed in rat choroidal epithelial cells. ${ }^{35)}$ If these proteins are generally expressed in the blood-brain and/or the bloodcerebrospinal fluid (CSF) barriers of mammals, these proteins appear to be involved in iron transport into the brain across the brain barrier system in the case of iron saturation of plasma transferrin (Fig. 1).

Judging from the concentrations of iron and transferrin in lumbar CSF from control humans, it is estimated that CSF transferrin is fully saturated with iron and that nontransferrin-bound iron is present in the CSF. ${ }^{36)}$ The presence of nontransferrin- 
bound iron in brain extracellular fluid, including CSF, was reported by Moos and Morgan ${ }^{37)}$ and Lipscomb et al. ${ }^{38)}$ Evidence for nontransferrin-mediated iron uptake is also indicated in glial cell cultures from unaffected control mice as well as HP mice. $^{39)}$

\section{Iron Distribution in the Brain under Hypo- transferrinemia}

The role of transferrin in the utilization of iron in the brain was studied using 7-day-old HP mice without administration of transferrin. ${ }^{40,41)}$ Twentyfour hours after injection of ${ }^{59} \mathrm{FeCl}_{3}$ into HP mice, ${ }^{59} \mathrm{Fe}$ was highly concentrated in the choroid plexus and ${ }^{59} \mathrm{Fe}$ concentrations in brain parenchyma were lower than in nonmutant mice. ${ }^{59} \mathrm{Fe}$ distribution in the brain of HP mice is similar to the case of the transient saturation of transferrin by iron loading. ${ }^{24)}$ In the brain of adult HP mice, the cellular and regional distributions of iron, transferrin, transferrin receptor, and ferritin are similar to those in normal mice, although transferrin in the brain is of exogeneous origin. ${ }^{30,42)}$ Interestingly, the iron concentration in the brain of 7-day-old HP mice is approximately three times higher than that in nonmutant mice. ${ }^{41)}$ The circulation of iron in the brain extracellular fluid might be impaired by the lack of transferrin, resulting in abnormal iron accumulation in the brain. It is likely that the management of iron is affected in the brain of HP mice. Brain transferrin may be involved in the management of iron in the brain.

Iron is a toxicant in excessive amounts; free iron can be cytotoxic by catalyzing the production of hydroxyl radical from hydrogen peroxide. ${ }^{43}$ Brain transferrin levels decrease with age and its decrease is dramatic when Alzheimer's disease or Parkinson's disease is superimposed on the aging process. ${ }^{44)}$ The transferrin/iron ratio, a possible index of iron mobilization capacity, is decreased in the globus pallidus and caudate putamen in both Alzheimer's and Parkinson's diseases. The decrease in transferrin levels in neurodegenerative diseases has been suggested as the cause of increased brain iron concentrations in these diseases. ${ }^{45-50)}$

\section{Conclusion}

Transferrin is important for physiological delivery of iron to the brain. Transferrin may be involved in the management of iron in the brain.

\section{REFERENCES}

1) Ward, J. H., Kushner, J. P. and Kaplan, J. (1982) Transferrin receptors of human fibroblast. Physiol. Rev., 67, 520-582.

2) Crichton, R. R. and Charloteaux-Wauters, M. (1987) Iron transport and storage. Eur. J. Biochem., 164, 485-506.

3) Hueber, H. A. and Finch, C. A. (1987) The physiology of transferrin and transferrin receptors. Physiol. Rev., 67, 520-582.

4) Levy, J. E., Jin, O., Fujiwara, Y., Kuo, F. and Andrews, N. C. (1999) Transferrin receptor is necessary for development of erythrocytes and the nervous system. Nat. Genet., 21, 396-399.

5) Takeda, A., Takatsuka, K., Connor, J. R. and Oku, $\mathrm{N}$. Abnormal iron delivery to the bone marrow in neonatal hypotransferrinemic mice. Biometals, in press.

6) Dickson, P. W., Aldred, A. R., Marley, P. D., GuoFen, T., Howlett, J. and Schreiber, G. (1985) High prealbumin and transferrin mRNA levels in the choroid plexus of rat brain. Biochem. Biophys. Res. Commun., 127, 890-895.

7) Aldred, A. R., Dickson, P. W., Marley, P. D. and Schreiber, G. (1987) Distribution of transferrin synthesis in brain and other tissues. J. Biol. Chem., 262, 5293-5297.

8) Espinosa de los Monteros, A., Kumar, S., Scully, S., Cole, R. and de Vellis, J. (1990) Transferrin gene expression and secretion by rat brain cells in vitro. J. Neurosci. Res., 25, 576-580.

9) Bartlett, W. P., Li, X.-S. and Connor, J. R. (1991) Expression of transferrin mRNA in the CNS of normal and jumpy mice. J. Neurochem., 57, 318322.

10) Bloch, B., Popovici, T., Levin, M., Tuil, D. and Kahn, A. (1985) Transferrin gene expression visualized in oligodendrocytes of the rat brain using in situ hybridization and immunohistochemistry. Proc. Natl. Acad. Sci. U.S.A., 82, 6706-6710.

11) Pollitt, E. and Leibel, R. L., Eds. (1982) IronDeficiency: Brain Biochemistry and Animal Behavior, Raven Press, New York.

12) Pollitt, E. and Metallinos-Katsaras, E. (1990) Iron deficiency and behavior: constructs, methods, and validity of the findings. In Nutrition and the Brain, vol. 8 (Wurtman, R. J. and Wurtman, J. J., Eds.), Raven Press, New York, pp. 101-146.

13) Markesbery, W. R., Ehmann, W. D., Alauddin, M. and Hossain, T. I. M. (1984) Brain trace element concentrations in aging. Neurobiol. Aging, 5, 1928.

14) Hill, J. M. and Switzer, R. C. (1984) The regional distribution and cellular localization of iron in the 
rat brain. Neuroscience, 11, 595-603.

15) Connor, J. R., Menzies, S. L., Marttin, S. M. and Mufson, E. J. (1990) Cellular distribution of transferrin, ferritin, and iron in normal and aged human brains. J. Neurosci. Res., 27, 595-611.

16) Taylor, E. M. and Morgan, E. H. (1990) Developmental changes in transferrin and iron uptake by the brain in the rat. Dev. Brain Res., 55, 35-42.

17) Larkin, E. C. and Rao, A. (1990) Importance of fetal and neonatal iron: adequach for normal development of the central nervous system. In Brain, Behavior and Iron in the Infant Diet, Springer-Verlag, New York, pp. 43-62.

18) de Arriba Zerpa, G. A., Saleh, M. C., Fernandez, P. M., Guillou, F., Espinosa de los Monteros, A., de Vellis, J., Zakin, M. M. and Baron, B. (2000) Alternative splicing prevents transferrin secretion during differentiation of a human oligodendrocyte cell line. J. Neurosci. Res., 61, 388-395.

19) Dadone, M. H., Kushner, J. P., Edwards, C. Q., Bishop, D. T. and Skolnick, M. H. (1982) Hereditary hemochromatosis: analysis of laboratory expression of the disease in 18 pedigrees. Am. J. Clin. Pathol., 78, 196-207.

20) Edwards, C. Q., Dadone, M. H., Skolnick, M. H. and Kushner, J. P. (1982) Hemochromatosis. Clin. Haematol., 11, 411-436.

21) Buys, S. S., Martin, C. B., Eldridge, M., Kushner, J. P. and Kaplan, J. (1991) Iron absorption in hypotransferrinemic mice. Blood, 78, 3288-3290.

22) Bernstein, S. E. (1987) Hereditary hypotransferrinemia with hemosiderosis, a murine disorder resembling human atransferrinemia. J. Lab. Clin. Med., 110, 690-705.

23) Craven, C. M., Alexander, J., Eldridge, M., Kushner, J. P., Bernstein, S. and Kaplan, J. (1987) Tissue distribution and clearance kinetics of nontransferrin-bound iron in the hypotransferrinemic mouse: a rodent model for hemochromatosis. Proc. Natl. Acad. Sci. U.S.A., 84, 3457-3461.

24) Takeda, T., Takatsuka, K., Sotogaku, N. and Oku, $\mathrm{N}$. Influence of iron-saturation of plasma transferrin in iron distribution in the brain. submitted.

25) Taylor, E. M. and Morgan, E. H. (1990) Developmental changes in transferrin and iron uptake by the brain in the rat. Dev. Brain Res., 55, 35-42.

26) Roberts, R. L., Fine, R. E. and Sandra, A. (1993) Receptor-mediated endocytosis of transferrin at the blood-brain barrier. J. Cell. Sci., 104, 521-532.

27) Fishman, J. B., Rubin, J. B., Handraham, J. V., Connor, J. R. and Fine, R. E. (1987) Receptormediated transcytosis of transferrin across the bloodbrain barrier. J. Neurosci. Res., 18, 299-304.

28) Broadwell, R. D., Baker-Cairns, B. J., Friden, P. M., Oliver, C. and Villegas, J. C. (1996) Transcytosis of protein through the mammalian cerebral epithelium and endothelium. III. Receptor-mediated transcytosis through the blood-brain barrier of bloodborne transferrin and antibody against the transferrin receptor. Exp. Neurol., 142, 47-65.

29) Descamps, L., Dehouck, M.-P., Torpier, G. and Cecchelli, R. (1996) Receptor-mediated transcytosis of transferrin through blood-brain barrier endothelial cells. Am. J. Physiol., 270, H1149-H1158.

30) Dickinson, T. K. and Connor, J. R. (1995) Cellular distribution of iron, transferrin and ferritin in the hypotransferrinemic (Hp) mouse brain. J. Comp. Neurol., 355, 67-80.

31) Nielsen, J. E., Jensen, L. N. and Krabbe, K. (1995) Hereditary haemochromatosis: a case of iron accumulation in the basal ganglia associated with a parkinsonian syndrome. J. Neurol. Neurosurg. Psychiatry, 59, 318-321.

32) Sotogaku, N., Oku, N. and Takeda, A. (2000) Manganese concentration in mouse brain after intravenous injection. J. Neurosci. Res., 61, 350356.

33) Jefferies, W. A., Food, M. R., Gabathuler, R., Rothenberger, S., Yamada, T., Yasuhara, O. and McGeer, P. L. (1996) Reactive microglia specifically associated with amyloid plaques in Alzheimer's disease brain tissue express melanotransferrin. Brain Res., 712, 122-126.

34) Rothenberger, S., Food, M. R., Gabathuler, R., Kennard, M. L., Yamada, T., Yasuhara, O., McGeer, P. L. and Jefferies, W. A. (1996) Coincident expression and distribution of melanotransferrin and transferrin receptor in human brain capillary endothelium. Brain Res., 712, 117-121.

35) Gunshin, H., Mackenzie, B., Berger, U. V., Gunshin, Y., Romero, M. F., Boron, W. F., Nussberger, S., Gollan, J. L. and Hediger, M. A. (1997) Cloning and characterization of a mammalian protein-coupled metal-ion transporter. Nature (London), 388, 482488.

36) Bradbury, M. W. B. (1997) Transport of iron in the blood-brain-cerebrospinal fluid system. $J$. Neurochem., 69, 443-454.

37) Moos, T. and Morgan, E. H. (1998) Evidence for low molecular weight, non-transferrin-bound iron in rat brain and cerebrospinal fluid. J. Neurosci. Res., 54, 486-494.

38) Lipscomb, D. C., Gorman, L. G., Traystman, R. J. and Hurn, P. D. (1998) Low molecular weight iron in cerebral ischemic acidosis in vivo. Stroke, 29, 487-492.

39) Takeda, A., Devenyi, A. and Connor, J. R. (1998) Evidence for non-transferrin-mediated uptake and release of iron and manganese in glial cell cultures from hypotransferinemic mice. J. Neurosci.Res., 51, 
454-462.

40) Takeda, A., Takatsuka, K., Oku, N. and Connor, J. R. (2000) Iron accumulation in hypotransferrinemic mouse brain. In Metal Ions in Biology and Medicine, Vol. 6 (Centeno, J. A., Collery, P., Vernet, G., Finkelman, R. B., Gibb, H. and Etienne, J.-C., Eds.), John Libbey Eurotext, Montrouge, France, pp. 123125.

41) Takeda, A., Takatsuka, K., Connor, J. R. and Oku, N. (2001) Abnormal iron accumulation in the brain of neonatal hypotransferrinemic mice. Brain Res., 912, 154-161.

42) Dickinson, T. K. and Connor, J. R. (1998) Immunohistochemical analysis of transferrin receptor: regional and cellular distribution in the hypotransferrinemic (hpx) mouse brain. Brain Res., 801, 171-181.

43) Zaleska, M. M. and Floyd, R. (1985) Regional lipid peroxidation in rat brain in vitro: possible role of endogeneous iron. Neurochem. Res., 10, 397-410.

44) Loeffler, D. A., Connor, J. R., Juneau, P. L., Snyder, B. S., Kanaley, L., DeMaggio, A. J., Nguyen, H., Brickman, C. M. and LeWitt, P. A. (1995) Transferrin and iron in normal, Alzheimer's disease, and Parkinson's diaease brain regions. J. Neurochem., 65, 710-716.

45) Connor, J. R., Menzies, S. L., St. Martin, S. M. and Mufson, E. J. (1992) A histochemical study of iron, transferrin, and ferritine in Alzheimer's disease brains. J. Neurosci. Res., 31, 75-83.

46) Craelius, W., Migdal, M. W., Luessenhop, C. P., Sugar, A. and Mihalakis, I. (1982) Iron deposits surrounding multiple sclerosis plaques. Arch. Pathol. Lab. Med., 106, 397.

47) Dexter, D. T., Wells, F. R., Lees, A. J., Agid, F., Agid, Y., Jenner, P. and Marsden, C. D. (1989) Increased nigral iron content and alterations in other metal ions occurring in brain in Parkinson's disease. $J$. Neurochem., 52, 1830-1836.

48) Good, P. F., Perl, D. P., Bierer, L. M. and Schmeidler, J. (1992) Selective accumulation of aluminum and iron in the neurofibrillary tangles of Alzheimer's disease: a laser microprobe (LAMMA) study. Ann. Neurol., 31, 286-292.

49) Thompson, C. M., Marksberry, W. R., Ehmann, W. D., Mao, Y.-Y. and Vance, D. E. (1988) Regional brain trace-element studies in Alzheimer's disease. Neurotoxicology, 9, 1-8.

50) Yehuda, S. and Youdim, M. B. H. (1988) Brain iron deficiency: biochemistry and behavior. In Brain Iron, Neurochemical and Behavioral Aspects (Youdim, M. B. H., Ed.), Taylor and Francis, London, pp. 89-114.

51) Moos, T. (1996) Immunohistochemical localization of intraneuronal transferrin receptor immunoreactivity in the adult mouse central nervous system. $J$. Comp. Neurol., 375, 675-692. 